\title{
Weitere Mittheilung über die paroxysmale, familiäre
} Lähmung.

\author{
Von \\ Dr. S. Goldflam, \\ Warschau.
}

(Mit 3 Abbildungen.)

Im Jahre 1890 babe ich ${ }^{1}$ ) über eine Familie berichtet, in der 11 Mitglieder von Anfällen completer Lähmung aller Extremitäten und des Rumpfes zeitweise heimgesucht werden. Auf Grund namentlich der längeren und genauen Beobachtung eines dieser Fälle und der in der Literatur zerstreuten Daten ${ }^{2}$ ) habe ich das wohlcharakterisirte und prägnante Krankheitsbild zu präcisiren versucht. Es besteht, in allgemeinen Zügen ausgedrückt, in einer bei bestem Wohlsein, plötzlich und schnell, besonders Nachts, sich bis zur completen Lähmung entwickelnden Schwäche der Extremitäten und des Rumpfes mit Verminderung resp. Aufhebung der Sehnen- und mancher Hautreflexe, mit Verminderung resp. Aufhebung der mechanisehen, sowie der indirecten und directen elektrischen Erregbarkeit (Cadaverreaction), während die Sensibilität, der Blasen-, Mastdarm- und sexuelle Reflex,

1) Zeitschrift für klin. Medicin. Bd. XIX. Suppl.

2) In Erb's Monographie über Thomsen'sche Krankheit finde ich einen Fall von Rothe (Statistischer Sanitätsbericht über die königl. preuss. Armee u. s.w. für 1879/1881. Berlin 1882. S. 5l), der von Erb mit Recht von der Thomsen'schen Krankheit zurickgewiesen wird, der aber, wie mir scheint, zur paroxysmalen Lähmung gehört. - Ausser dem Falle von Hirsch, von dem noch unten die Rede sein wird, findet sich im Centralblatt f, klin. Med. 1894. Nr. 11 ein kurzes Referat über eine mir unzugängliche Arbeit von Buor (Periodic paralysis with the report of a case. Pacific record 1893. Sept. 15). - Ganz in der letzten Zeit sah ich ein 8 jăhriges Mädchen, dass seit 3 Jahren an anfallsweiser, so ziemlich wöchentlich wiederkehrender Lähmung leidet. Dieselbe setzt immer mit Erbrechen ein. Zuerst waren nur die Beine gelähmt, in der letzten Zeit auch der Rumpf, Arme und Kopf. Bestehen der Lähmung bis 24 Stunden. Die Bewegungsfähigkeit kehrt rasch wieder. Ein jüngeres Geschwister, das im 3. Lebensjahre gestorben ist, litt ebenfalls an solcher Läbmung aller Glieder. Ich enthalte mich weiterer Ausführungen, da die Beobachtung noch richt geschlossen ist. 
die Sinnesorgane, das Sensorium, sowie sämmtliche von den cerebralen Nerven versorgten Muskeln intact bleiben. Nach etwa 24-48 stiundigem Bestehen der completen Lähmung tritt dieselbe, ebenso schnell, im Verlaufe von einigen Stunden, vollständig zurück, die elektrische Erregbarkeit, die Reflexe kehren wieder, der Patient wird vollkommen gesund, bis ein neuer Anfall ihn bewegungsunfähig macht,

Solche Anfälle erscheinen in verschieden langen Zwischenräumen, von einigen Tagen bis Jahren, auch bei den Mitgliedern derselben Familie, doch ist ein gewisser Typus fuir jeden Fall erkennbar. Die Krankheit ist nämlich eine familiäre, sie erscheint oft bei vielen Mitgliedern der Familie, die Vererbung ist eine gleichartige und durch ganze Geschlechter nachweisbar; andere Nervenkrankheiten kommen gewöhnlich in der Familie nicht vor. Betreffs der näheren Details, der Symptomatologie der grossen, leichten und abortiven Anfälle, der künstlich hervorgerufenen u. s. w. verweise ich auf meine oben citirte Arbeit.

Was die Pathologie des Leidens anbetrifft, so habe ich die Vermuthung ausgesprochen, dass die Muskeln selbst, vielleicht deren Nervenendigungen vom Krankheitserreger afficirt sind. Das gesammte klinische Bild, namentlich aber das paroxysmale Auftreten der Lähmung, das elektive Befallensein der Motilität u. s. w. schien die Annahme eines toxischen Momentes zu berechtigen, eines Giftes, das im Organismus selbst sich bildet, sich zeitweise anhäuft und deletär auf die Muskeln resp. ihre Nervenendigungen einwirkt (ich wusste damals nicht, dass diese Hypothese einer Autointoxication bereits von Bernhardt in seinem Referate über den Westphal'schen Fall ausgesprochen wurde). Die Versuche mit dem Harne des Patienten nach der Methode von Bouchard, die ich damals angestellt habe, schienen diese Hypothese in gewissem Maasse zu unterstiitzen, denn es hat sich herausgestellt, dass der während des Anfalles ausgeschiedene Harn viel toxischere Eigenschaften, einen höheren sog. Coeficient urotoxique besitzt, als der Harn von freien Intervallen, dass bei den Kaninchen die Lähmung und das Verschwinden der Reflexe früher auftreten in den Versuchen mit Anfallsurin, als in den mit dem Harne von gesunden Tagen. Trotzdem konnte ich nicht umhin, mich reservirt über den Werth der Methode auszusprechen und die Beweiskräftigkeit der Schlüsse in Frage za stellen.

In diesem Jahre hatte ich wieder Gelegenheit, denselben Kranken und seinen älteren Bruder längere Zeit zu beobachten. Ich habe an ihnen Versuche angestellt, die ganz unerwartete Ergebnisse für die Patbologie der Störung geliefert haben. 
Zur Ergänzung des im Jahre 1890 geschilderten Bildes will ich zuerst einige Details hinzufügen. Seit dieser Zeit kamen die Anfälle bei M. Rydel immer häufiger wieder vor, im Sommer etwa $1-2$ mal in der Woche, im Winter etwa 1 mal in zwei Wochen; sie dauern circa 48-60 Stunden, wenn die Anfälle seltener auftreten, circa 24 Stunden, wenn häufiger. Der Kranke ist noch immer von dem Einflusse der Nahrung auf die Anfälle und von der Schädlichkeit derselben während des Anfalles überzengt; dass dies unbegründet, dafür wird unten der Beweis geliefert.

In der diesjährigen Beobachtungszeit haben die Anfälle dasselbe Gepräge beibehalten; es giebt wenige Krankheiten mit so auffallenden und beinahe stereotypisch sich wiederholenden Symptomen. Doch haben manche kleine Einzelheiten eine Modification erfahren. Während vor vier Jahren sich das Herannahen des Anfalles durch das Aufhören des in der Zwischenzeit vorhandenen Juckens kundgab, trat diesmal das Jucken überhaupt in den Hintergrand. Dagegen kündigte sich der herannahende Anfall diesmal sehr oft durch ein Gefühl von Kälte an, welches zuerst in den Beinen, dann in den Armen verspürt wird, also dieselbe Reihenfolge wie die später eintretende Lähmung behält; nur manchmal verspürte der Kranke vor dem Anfalle ein Durstgefühl. Doch waren beide Phänomene nicht auffallend, und meistens verrieth nichts den Anfall; der Kranke legte sich ganz gesund ins Bett, und in der zweiten Hälfte der Nacht erwachte er mit vollständiger Lähmung der Glieder. Die Anfälle treten nämlich gewöhnlich Nachts auf, am Tage nur dann, wenn der Kranke zufällig einschläft, im wachen Zustande nur selten; Nachts beginnt auch meistens die Besserung. In der früheren Beobachtungszeit endete der Anfall gewöhnlich mit profusem Schweissausbruch und Wiederkehr des Juckens; dieses Mal waren diese Symptome viel geringer ansgesprochen.

Die diesjährige Beobachtung verzeichnete viele unvollständige Anfälle, das heisst solche, in welchen die Schwäche sich nicht zur absoluten Lähmung steigerte, die Reflexe theils aufgehoben, theils nur herabgesetzt waren, ebenso wie die elektrische Erregbarkeit, Anfälle in welchen die Beine mehr als die Arme und vice versa ergriffen waren u. s. w. Es kam auch vor, dass einzelne Gliederabsehnitte mehr als die anderen gelähmt waren, z. B. die Fuss- und die Zehengelenke stärker als die Knie- und Hüftgelenke. Einmal documentirte sich der Anfall nur durch Sehwäehe der Finger. Es ist daher verständlich, dass in diesen unvollständigen Anfällen die Sehnenreflexe ein verschiedenes Verbalten, je nach dem Grade und Extensität der Lähmung zeigten; während sie alle im vollentwickelten Anfalle aufgehoben sind, feblte 
z. B. nur der rechte Achillessehnen- und Plantarreflex bei grösserer Schwäche des Fusses. Ein ungleiches Verhalten der Sehnenreflexe kam am Ende des starken Anfalles zu Stande; wenn z. B. die Füsse friuher die Beweglichkeit erlangten, als andere Abschnitte der Beine, dann waren die Achillessehnenreflexe schon vorhanden, von den Kniereflexen aber noch keine Spur zu sehen. Nicht so selten waren die Sehnenreflexe auch nach Abklingen des Anfalles schwach und nur mittelst Jendrassik's Handgriff hervorzurufen.

Dasselbe lässt sich von den Hautreflexen (Sohlen-, Cremaster- und Bauchreflexen) sagen, sie schwinden im completen Anfalle, sind im unvollständigen herabgesetzt, resp. ungleich auf beiden Seiten u. s. w.

Die unvollständigen Anfälle haben auch meist eine kürzere Dauer, manchmal können sie aber in complete Lähmung übergehen. Selten gelang es dem Kranken, die Ausbildung des Anfalles dadurch zu rerhüten, dass er bald nach Verspürung der Schwäche stundenlang mühsam herumging, öfters entwickelte sich trotzdem der Anfall in voller Stärke. Von grösserem Erfolge war gewöhnlich die forcirte Bewegung gekrönt, wenn die Schwäche sich während eines Nacbmittagsschlafes etablirte.

Der so zu sagen klassische Anfall besteht aus drei Stadien, der In- und Extensitätszunahme der Lähmung, des Bestehens derselben auf einer gewissen Höhe und schliesslich der Abnahme und Verschwinden der Erscheinungen. In irregulären Anfällen kommen Rückfälle im Stadium der Besserung vor; der Kranke verfällt wieder in Lähmung, nachdem er schon die Beweglichkeit der Glieder in gewissem Maasse erlangt hatte.

Schon im Jahre 1890 habe ich über manche Anomalien der Circulation im Anfalle berichtet, so über Bradycardie und Schwäche der Herzcontractionen. In diesem Jahre constatirte ich einige Mal Arhythmie, ein schwaches systolisches Blasen an der Herzbasis mit schwacber Accentuation des II. Tones, seltener einen langgezogenen unreinen $I$. Ton an der Herzspitze, aber keine Herzyergrösserung, keine Stauungserscheinungen, keine Pulsbeschleunigung, im Gegentheil Bradycardie. Meistens aber war im Anfalle nur ein dumpfer, kaum hörbarer I. Ton constatirbar. Uebrigens konnte man die genannten Erscheinungen (ausser Arhythmie) manchmal auch ausserhalb des Anfalles wahrnehmen, sie waren flüchtiger Natur, sie kamen und schwanden ohne äussere Veranlassung. Dennoch documentiren diese abnormen Erscheinungen eine Betheiligung des Herzens, wenn anch in viel geringerem Grade, als in den Fällen von Westphal ${ }^{1}$ ) und $\mathrm{Hirseh}^{2}$ ), in welchen

1) H. Oppenheim, Charité-Annalen. XVI. S. 350 .

2) Deutsche med. Wochenschr. 1891. Nr. 32. 
während der Anfälle acut eine Mitralinsufficienz sich ausbildete, deren Zeichen in den freien Intervallen nicht vorhanden waren; aber auch in diesen Beobachtungen waren keine Compensationsstörungen, keine Beschleunigung des Pulses vorhanden und traten die Herzsymptome im Falle Westphal's, eben wie in meinem, nicht in jedem Anfalle auf.

Die Unzulässigkeit der Angabe, dass Magendarmstörungen die Anfälle hervorzurufen vermögen oder dieselben unterhalten, wurde endgültig durch die Thatsache erbärtet, dass Patient während der Beobachtungszeit eine Typhlitis und Perityphlitis (Appendicitis?), infolge eines Diätfehlers durchgemacht hat, die aber keinen Anfall zur Folge hatte. ${ }^{1)}$ Ausserdem wurden vielfache Magensondirungen vorgenommen, sowohl niichtern, als nach Probemahlzeiten; die exacten Untersuchungen haben nur eine unbedeutende Hyperacidität ergeben, wie sie bei nervösen Leuten oft vorzukommen pflegt. In den Faeces wurden keine Helminthen gefunden, bacteriologisch eine reine Cultur von Bacterium coli. Längere Darreichung von Menthol bis 1,0 täglich blieb ohne Erfolg. Auch der Versuch mit Salol $4 \times 1,0$ täglich scheiterte.

Die Anomalien der elektrischen Erregbarkeit werde ich zusammen unten besprechen, da sie bei beiden Bridern identisch sind. Der ältere Bruder, S. Rydel, jetzt 28 Jahre alt, bekam den ersten Anfall im 18. Lebensjahre, bis zum 20. Jahre zusammen drei Anfälle. Wäbrend des Militärdienstes traten sie sehr häufig auf, beinahe wöchentlich, mindestens ein- oder zweimal monatlich. Der Simulation verdächtig, wurde er mit Kriegsgericht bedroht, glücklicher Weise ohne Consequenzen. Seit drei Jahren hat er den Dienst verlassen und nur drei grosse Anfälle gehabt, ausserdem aber viele kleinere, die sich ebenfalls nach dem Schlaf einstellen und durch Schwäche der ganzen Museulatur, die nach einigen Stunden verschwindet, kundgeben. Die grossen Anfälle zeichnen sich durch nngewöhnliche Intensität aus, die Lähmung ist, wenn möglich, noch vollständiger und ausgebreiteter als bei M. Rydel, die geringste Bewegung mit den Extremitäten, Rumpfe, Kopfe, ist anmöglich, das Husten, das Schleimentfernen ist hochgradig beeinträchtigt; in einem Anfalle kam es sogar zu einem bedrohlichen asphyktischen Zustande, angeblich nach Genuss von Kartoffeln. Seit dieser Zeit theilt er die Ueberzeugung des jüngeren Bruders, dass Nahrungsaufnahme während des Anfalles schädlich sei, und hält absolute Carenz während der Dauer des Anfalles bei, die gewöhnlich drei Tage beträgt. Auch bei ihm sind Antlitz, Zunge, Schlund, Kehlkopfmuskeln, Sinne, Psyche frei, auch hier beginnen

1) Erinnert soll daran werden, dass bei dem oben erwähnten 8 jährigen Mädchea der Anfall jedesmal mit Erbrechen einsetzt. 
die Anfälle Nachts; nach dem Erwachen ist Patient bereits vollständig gelähmt. Das Ende des Anfalles verräth sich dem Kranken durch ein Juckgefühl im Kopfe, zuerst stellen sich Kopfbewegungen ein; die Erholungszeit nimmt nur ein paar Stunden in Anspruch, manchmal erwacht er vom Schlafe völlig hergestellt.

Bei dem sonst gesunden, kräftig gebauten Manne, dessen innere Organe keine Anomalien zeigen, fällt auf den ersten Blick die ausserordentlich stark entwickelte Musculatur auf, die Muskelbäuche springen mit ihren bedentenden Reliefs unter die Haut vor. Es ist dies um so auffallender, da der Kranke zu der Bevölkerungsschicht gehört, die sich ganz ungenügend ernäbrt. Auch ist die grobe Kraft dieser fast athletischen Muskeln verhältnissmässig gering, sie beträgt für die rechte Hand nur $50 \mathrm{Kgrm}$, für die linke $40 \mathrm{Kgrm}$. (bei dem jüngeren Bruder 29 und $30 \mathrm{Kgrm}$.). Wie erstaunt war ich aber, als bei der elektrischen Untersuchung des Nervenmuskelapparates sich ganz erhebliche Veränderungen vorfanden. Es war mir schon im Jahre 1890 bei dem jüngeren Bruder in den freien Intervallen eine Abweichung der elektrischen Erregbarkeit in den kleinen Handmus. keln aufgefallen, nämlich Herabsetzung derselben und träge Contraction, sogar Aenderung der Zuckungsformel bei galvanischer Reizung, eine Modalität der Mittelform der Entartungsreaction, wie ich mich damals ausdrückte. Auch an manchen anderen Muskeln wurde die schwache, sogar träge Contraction verzeichnet, so im Tibialis anticus, Peroneus, Gastroenemius; am Flexor digit. com. antibrachii aber das frühzeitige Auftreten der KaSD. Das unerwartete Resultat der elektrischen Untersuchung bei dem in voller Gesundheit sich befindenden älteren Bruder gab mir nun Veranlassung, eingehend dieselbe auch bei M. Rydel einer erneuten Prüfang zu unterziehen, die übereinstimmende Ergebnisse bei beiden Brìdern geliefert hat.

Wir werden gesondert die elektrischen Erregbarkeitsverhältnisse im Anfalle und ausserhalb desselben, im relativen Gesundheitszustande, besprechen, da die Reactionen ganz different sich verhalten.

In den Intervallen, in welchen die Brüder Rydel sich ganz wohl fühlen, ist die directe und indirecte elektrische Erregbarkeit sowohl anf faradische als galvanisehe Ströme entschieden herabgesetzt. Die Stromintensität, die soeben genügte, um eine Contraction hervorzurufen, löst bald keine Zuckung mehr aus. Es ist dies eine Erschöpfbarkeit der Nerven und Muskeln für schwächere faradische und galvanische Ströme, die ausser durch kurzdauernde, momentane Reize noch durch stabiles Einwirken des galvanischen Stromes begünstigt wird. Ruhe fübrt die Erregbarkeit bis zu den ursprünglichen Werthen zurück.

Muskeln. Die galvanische Reizung derselben ruft eine typisch träge 
Contraction hervor. KaSZ tritt meistens zuerst auf, nur selten (z. B. an den kleinen Handmuskeln) tiberwiegt die An, oder ist dieselbe der Ka gleich. KaSTe ist schon bei verhältnissmässig geringen Stromwerthen zu erzielen, beinahe denselben, bei welchen die AnSZ und $\mathrm{AnOz}$ zu Tage tritt. Auf KaSTe folgt manchmal, aber lange nicht immer, Nachdauer der Contraction. KaOZ liess sich ebenfalls nicht selten leicht, schon bei nicht starken Strömen, erreichen; nur sehr selten trat sie vor $\mathrm{AnOZ}$ auf. Ab and zu konnte ich eine zweifellose AnSTe hervorrufen.

Bei directer faradischer Reizung fiel die Zuckung ebenfalls träge aus (faradische Entartungsreaction), manchmal konnte man das langsame Anschwellen der Contraction und das langsame Abklingen derselben constatiren (faradische EaR mit Nachdaner der Zuckung).

Nerven. Bei indirecter galvanischer Reizung stellen sich die Zackungen als tonisch, träge vor, wenn auch diese Erscheinung weniger ausgesprochen ist, als bei directer galvanischer Reizung (partielle EaR mit indirecter Zuckungsträgheit nach $\mathrm{Erb}$ ). An den Nerven war das verhältnissmässig frühe Auftreten der KaSTe und $\mathrm{KaOZ}$, bei Stromwerthen, die den für $\mathrm{AnOZ}$ und $\mathrm{AnSZ}$ nahe standen, noch mehr als bei den Muskeln auffallend. Auch konnte man manchmal, aber lange nicht constant, die Nachdauer, die der KaSTe folgte, beobachten. Selten gelang es sogar AnSTe zu erhalten.

Tonisch, langgezogen sind die Contractionen auch bei indirecter faradischer Reizung.

Diese abnormen Reactionen betrafen die Nerven und Muskeln der Extremitäten und des Rumpfes, in manchen Bezirken waren sie mehr, in anderen weniger ausgesprochen. Stark betheiligt war der motorische Ast des Accessorius, N. museulocutaneus, axillaris, N. tibialis post., N. peroneus. Nicht alle Aeste eines Nervenstammes verhielten sich gleichmässig in Betreff der elektrischen Reactionen, so z. B. bot der Triceps brachii typisch tonische und träge Zuckungen bei galvanischer und faradischer Reizung, die Extensoren aber des Vorderarms sowohl bei directer, als indirecter Reizung an der Unschlagstelle des $\mathrm{N}$. radialis reagirten ziemlich prompt. Dasselbe gilt für den N. medianus and ulnaris; während die kleinen Handmuskeln sich träge contrahirten, waren die Znckungen am Vorderarm sowohl bei directer als indireeter Reizung prompt. Man konnte anch wahrnehmen, dass in den Nervenmuskelterritorien, in welchen im Allgemeinen ziemlich blitzartige Zuckungen vorherrschten, die AnSZ gewöbnlich träger ausfiel; manchmal fiel auch auf, dass die bei schwachen und mittleren Strömen tonisch sich gestaltende Zuckung ziemlich blitzartig wurde bei Verstärkung des Stromes.

Im Anfalle waren im selben Maasse diejenigen Nervenmuskelterritorien gelähmt, die ausgeprägte abnorme Reactionen (die wir als eine Modification der partiellen EaR mit indirecter träger Zuckung bezeichnen wollen), wie anch die, welche nur unbedeutende Anomalien zeigten. Denn Herabsetzung der elektrischen Erregbarkeit war tiberall vorhanden, auch in dem Facialisgebiete, welches von der Lähmung regelmässig verschont blieb und in welchem sogar die AnSZ nicht blitzartig ansfiel, KaSTe und $\mathrm{KaOZ}$ leicht auszulösen waren.

Wesentlich anders gestaltet sich die neuromusculäre elektrische Er- 
regbarkeit im $A \mathrm{n}$ falle selbst. Wäbrend in den freien Intervallen qualitative Veränderungen in den Vordergrund traten, iiberwiegen hier die quantitativen. Die elektrische neuromusculäre Erregbarkeit sinkt nämlich im Anfalle bis zum vollständigem Erlöschen herab. Der Grad der Herabsetzung der elektrischen Erregbarkeit ist der Intensität der Lähmung proportional. Ist der Anfall nicht vollständig ansgebildet und besteht meistens nur hochgradige Parese, dann haben wir nur starke Herabsetzung der indirecten und directen elektrischen Erregbarkeit, ist aber der Anfall vollkommen ausgeprägt und ist die Lähmung eine complete, dann vermögen auch die stärksten Ströme (RA $=0$, mehr als 50 M.-A), sowohl vom Nerven als vom Muskel, keine Zuckung hervorzurufen (Cadaverreaction). Da aber meistens im incompleten Anfalle manche Nerventerritorien vollständig gelähmt sind, im completen Anfalle manche weniger afficirt sind, so haben wir ein Mal ein Ueberwiegen der starken Herabsetzung der elektrischen Erregbarkeit, ein anderes $\mathrm{Mal}$ ein Ueberwiegen der Cadaverreaction.

Die Herabsetzung, resp. das Erlöschen der elektrischen Erregbarkeit betrifft sowohl diejenigen Nervenmuskelgebiete, die eine ansgeprägte partielle EaR mit indirecter Zuckungsträgheit in den Intervallen darbieten, als auch die, welche nur geringe Veränderungen der elektrischen Reaction zeigen. Der Charakter der Zuckung bleibt im Anfalle bei Herabsetzung der Erregbarkeit tonisch, träge in denjenigen Gebieten, wo anch in den Intervallen solche träge Reaction vorherrscht, ja, vielleicht wird die träge Contraction im Anfalle noch mehr ausgesprochen, ausserdem werden die Zuckungen schwach, tonisch auch in denjenigen Nervenmuskelgebieten, von welchen in den Intervallen ziemlich blitzartige Contractionen sich auslösen liessen.

In einem und demselben Anfalle müssen nicht alle von einem Nervenstamm versorgten Muskeln in demselben Maasse gelähmt sein, demgemäss gestaltet sich auch die elektrische Erregbarkeit rerschieden und kann sie in manchen Muskeln erloschen, in anderen nur stark herabgesetzt sein. In einem sich tiber einjge Tage hinziehenden Anfalle können eines Tages diese Muskeln, des anderen Tages jene Muskeln desselben Nervengebietes ihre elektrische Erregbarkeit vollständig einbüssen. Endlich kommt es nicht selten vor, dass zur selben Zeit der Grad der Herabsetzung der elektrischen Erregbarkeit in diversen Muskeln eines Nervengebietes verschieden ist, und braucht man zur Hervorrnfung der Zuckung, sowohl indirect als direct, Ströme von ungleicher Intensität.

Obwohl die Untersuchung der elektrischen Erregbarkeit in den ersten Stunden des Anfalles dadurch erschwert ist, dass die Lähmung schnell, zumal Nachts, sich entwickelt, so scheint doch, dass die vermuthete Noxe, die den Anfall hervorruft, hauptsächlich auf die Muskeln ihre Wirkung ausübt, denn die Herabsetzung der elektrischen Erregbarkeit war in den Muskeln hochgradiger als in den Nerven. Die directe faradische Erregbarkeit erloseh schneller, als die directe galvanische. In den stark von der Lähmung heimgesuchten Gebieten gelang es noch eine schwache Zuckung: vom Nerven auszulösen, während die entsprechenden Muskeln für stärkste Ströme stumm blieben.

Bei vorhandener starker Herabsetzung der elektrischen Erregbarkeit nahm man wahr, dass die Zuckungen sich nicht vergrösserten mit Ver- 
stärkung des Stromes, oder aber in nicht geradem Verhältnisse. Diese Erscheinung der Erschöpfbarkeit war in den Anfällen noch mehr ausgesprochen, als in den Intervallen, indem bald die soeben angewendete Reizstärke nicht genügte, um Zuckung hervorzurufen; dieses gilt nicht allein für schwache Ströme, sondern anch für mittlere. Ebenso wie in den Intervallen wirkten momentane Reize und die stabile Durchleitung des galvanischen Stromes herabsetzend anf die elektrische Erregbarkeit.

Die geschilderten Anomalien beziehen sich sowohl auf directe als indirecte faradische und galvanische Erregbarkeit im Anfalle. Sie betrafen, ebenso wie die Lähmung, die Extremitäten und den Rumpf; nur die Gesichtsmuskeln, die Zunge, der Schlund u. s. w. blieben, wie von der Lähmung, so auch von der starken Herabsetzung der elektrischen Erregbarkeit verschont.

Das Obige ist das Resultat sehr zahlreicher Untersuchungen, die ich im Einzelnen nicht anführen kann.

Neben diesen hochgradigen Anomalien der elektrischen Erregbarkeit waren constante Veränderungen der mechanischen Nerven-und Muskelerregbarkeit im Anfalle vorhanden, die, wenn auch keine solche Wichtigkeit beanspruchen, dennoch eine Berïcksichtigung verdienen. In den Intervallen gelang es ohne besondere Schwierigkeit von den zugänglichen Nerven, nämlich vom $\mathbf{N}$. radialis, medianus, ulnaris, peronens mittelst mechanischer Reizung eine ziemlich lebhafte Zuckung im versorgten Muskelgebiete auszulösen. Ich bediente mich dabei eines Handgriffes, welcher darin bestand, dass ich, den Nerven kräftig mit dem Daumen an den Knochen drïckend, plötzlich von ihm herunterratschte; mittelst dieses Handgriffes erhielt ich bessere Resultate, als durch Beklopfen mit dem Percussionshammer. Nun vermochte derselbe Handgriff keine Zuckung im Anfalle hervorzurufen; man konnte den Nerv noch so stark drïcken, beklopfen - die Muskeln contrahirten sich nicht. Sie blieben auch stumm in den unvollständigen Anfällen, wenn die elektrische Erregbarkeit in den entsprechenden Bezirken nur stark gesunken war. Es schien sogar, dass die mechanische Nervenerregbarkeit früher erlosch und später zurïckkehrte, als die elektrische, doch muss man die Unvollkommenheit der Methode in Erwägung ziehen. In manchen Anfällen konnte man feststellen, dass nicht das ganze Gebiet des Nerven für mechanische Reize unerregbar war; während die Mehrzahl der Muskeln stumm blieben, contrahirten sich nur diejenigen, die auch von der completen Lähmung verschont blieben und auf elektrische Reize reagirten.

Interessante Resultate hat die Untersuchung der mechanischen Erregbarkeit der Muskeln selbst, der sogenannten idiomusculären Erregbarkeit, geliefert. Diese wurde durch Beklopfen mit dem Percussionshammer geprüft und ergab in den Intervallen, ebenso wie bei Gesunden, eine fasciculäre Contraction, resp. ein Zusammenziehen des ganzen Muskels, und ausserdem einen an der Stelle des Anschlagens quer über dem Faserverlaufe sich bildenden Wulst. Der Untersehied vom Gesunden bestand darin, dass die fasciculäre resp. Totalzuckung des Muskels eine tonische, typisch träge war, zumal an den Muskeln, welche die Abart der partiellen EaR mit indirecter Zuckungsträgheit darboten, also namentlich am Biceps, Triceps brachii, Deltoideus, Cucullaris, Pectoralis, an den 
kleinen Handmuskeln, Gastrocnemius u. s. w.; an anderen Muskeln, z. B. des Vorderarms, waren die Contractionen ziemlich prompt.

Anders im Anfalle, In den gelähmten Muskeln verschwinden zuerst vollständig die fasciculären Zuckungen, es bilden sich nur beim Beklopfen die queren Wülste, welche allmählich sich emporbeben und allmählich sinken, endlich schwinden auch diese in den vollkommen gelähmten Muskeln, die dann auf mechanische Reize gar nicht reagiren, man mag so stark beklopfen, wie man will. Erst mit der Rïckkehr der Function, der elektrischen Erregbarkeit erscheint die mechanische Erregbarkeit der Muskeln wieder und zwar zuerst die Wulstbildung, dann die fasciculäre Contraction. Es scheint sogar, dass sie friiher wiederkehrt, als die mechanische Nervenerregbarkeit und die Reaction auf elektrische Reize.

Das gesonderte Verschwinden und Erscheinen der queren Wiulste und fasciculären Contractionen spricht dafür, dass dieselben zwei gesonderte Phänomene der mechanischen Muskelerregbarkeit darstellen. Es ist möglich, dass die fasciculären Zuckungen, resp. die Zusammenziehung des ganzen Muskels von Reizung, oder Erschütterung des zugehörigen Nervenmuskelastes herrührt, die queren Wülste aber ein Effect der directen Reizung der Muskelsubstanz selbst sind.

Ueber das Verhalten der Sehnenreflexe wurde schon oben und ausführlicher in meiner ersten Arbeit mitgetheilt. Ich will noch hinzufügen, dass schon in den Intervallen der Charakter der Contraction des entsprechenden Muskels bei Beklopfen seiner Sehne ein ausgesprochen langgezogener, träger ist, namentlich an den Muskeln, die die Abart der partiellen EaR und tonische Zuckung bei mechanischer Reizung darbieten, also in dem Gastrocnemius und im Triceps brachii. Im unvollständigen Anfalle, wenn die Sehnenreflexe nur stark herabgesetzt sind, tritt dieser tonische Charakter noch mehr hervor und wird auch bei Prüfung des Patellarreflexes sichtbar.

Von den oben erörterten Erscheinungen nehmen die Veränderungen der elektrischen Erregbarkeit unbestritten den ersten Rang ein. Es ist ja ohnehin eine höchst merkwïrdige Thatsache, dass bei anscheinend gesunden Menschen mit prächtig entwickelter Musculatur sich solche bedeutende Störungen der elektrischen Nervenmuskelerregbarkeit vorfinden, welche im Anfalle sich zum vollständigen Erlöschen jeder Reaction steigern. Glicklicher Weise sind wir nicht ohne jede Analogie in der Pathologie und werden wir unwillkürlich an die Thomsen'sche Krankheit erinnert, bei welcher ebenfalls qualitative Veränderungen der elektrischen Erregbarkeit, die sogenannte MyR obwaltet und einen hervorstechenden $\mathrm{Zug}$ der Erkrankung bildet. Wir werden weiter unten sehen, dass ausser der elektrischen Reaction, dem familiären Charakter, noch ein dritter 
hüchst wichtiger Contactpunkt zum Vergleiche beider Krankheiten herausfordert.

Was die elektrische Erregbarkeit anbelangt, so ist die träge, tonische Contraction bei directer galvanischer Reizung beiden Erkrankungen gemeinsam. Nun aber sind bedeutende Differenzen vorhanden, die die MyR genügsam von der hier waltenden Modification der partiellen EaR mit indirecter Zuckungsträgheit unterscheiden. So ist bei indirecter faradischer Reizung mit mässig starken Strömen in der Thomsen'schen Krankheit Nachdauer der Zuckung vorhanden, in der paroxysmalen Lähmung war diese Erscheinung nicht zu constatiren. Während in der Th $0 \mathrm{~ms}$ en'schen Krankheit nur labile galvanische Ströme bei indirecter Reizung tonische, unzweifelhaft nachdauernde Contractionen auslösen, tritt bier die tonische Contraction schon bei Einzelreizen hervor, Nachdauer aber folgt nur, und lange nicht constant, auf KaSTe. Bei der Thomsen'schen Krankheit tritt die Nachdauer der Zuckung bei directer faradischer Reizung in den Vordergrund der Erscheinungen - hier kommt sie nur selten zum Vorschein; dort kommen wogende, oscillirende Muskelcontractionen zu Stande, hier faradische EaR. In der Thomsen'schen Krankheit ist die directe galvanische und faradische Erregbarkeit gesteigert - in der paroxysmalen Lähmung ist dieselbe, ebenso wie die indirecte, herabgesetzt; dort treten nur Zuckungen ein bei Schliessungen des Stromes, hier auch bei Oeffnungen, ja $\mathrm{KaOZ}$ ist leicht hervorzurufen. In der paroxysmalen Lähmung tritt KaSTe schon bei verhältnissmässig geringen Stromwerthen auf, bei der Thomsen'schen Krankheit bei starken galvanischen Strömen; in der ersten Krankheit gelang es manchmal sogar AnSTe zu erhalten. Während bei der Thomsen'schen Erkrankung schwache Ströme manckmal blitzartige Zuckungen geben, stärkere aber eine träge Reaction anslösen, walten hier umgekehrte Verhältnisse $o b$, nämlich bei schwachen Strömen kommen manchmal tonische Zuckungen, bei stärkeren prompte zum Vorschein; ausserdem ist hier die eigenthïmliche Erscheinung der Erschöpfbarkeit der Contraction bei schwachen und mittleren Strömen vorbanden, von der in der Thomsen'schen Krankheit keine Erwähnung gethan wird. ${ }^{1}$ ) Bei der letzteren ist die Erscheinung der rhythmisch wellenförmigen Contraction bei stabiler Stromeinwirkung höchst anffallend - hier konnte man dieses Phänomen nicht hervorrufen. Bei

1) Das Phănomen der Erschöpfbarkeit wurde schon von Benedict beobachtet, ganz in der letzten Zeit von Jolly in: den Fällen von Myasthenia gravis pseudoparalytica v. in dem von mir gen. heilbaren bulbärparalytischen Symptomencomplexe (Berliner klin. Wochenschr. 1895. Nr. 1, Deutsche Zeitschrift für Nervenheilkunde. Bd. VI). 
der Thom s e n'schen Krankheit ist die MyR an den Gesichts- und Kaumuskeln, Zunge ermittelt worden, welche in der paroxysmalen Lähmung beinahe verschont bleiben.

Im Folgenden sollen die Harnanalysen angeführt werden; sie wurden sämmtlich von Herrn Coll. Knaster ausgeführt, dem ich für die mühevolle und zeitraubende Arbeit meinen herzlichsten Dank ausspreche (s. Tabelle I).

Nach Loebisch ${ }^{1}$ ) beträgt beim Gesunden die Menge der gepaarten Schwefelsäuren im Harne in 24 Stunden im Mittel 0,25 (0,62 Maximum, 0,094 Minimum), das Mengenverhältniss der als Alkalisulat im Harn enthaltenen Schwefelsäure zu der in Form der gepaarten Schwefelsäuren vorkommenden ist bei Gesunden durchschnittlich wie $10: 1$, bei Schwankungen von $6: 1$ und $15: 1$. Vergleichen wir diese Zahlen mit den bei Rydel ermittelten, so sehen wir, dass sowohl absolut als relativ die Menge der gepaarten Schwefelsäuren auch im Anfalle nicht von den physiologischen Grenzen abweicht. Nur eine Thatsache tritt hervor, nämlich dass die Menge der gepaarten Schwefelsäuren im Anfalle grösser war, als in den Intervallen, und betrug ihr Verbältniss zur Gesammtschwefelsäure wie 1: 7,69; 1: 7,8; $1: 6,5$, gegen $1: 13,2,1: 10,59,1: 12,1$ in den Intervallen. Noch auffallender war die bedeutende Vermehrung des Indicans im Anfalle.

Man könnte versucht sein, diese Befunde fuir die Theorie der Krankheit heranzuziehen, im Sinne einer vom Darme erfolgten Autointoxication. Doch wird man schwerlich im speciellen Falle eine grössere Bedeutung diesen, durch die Harnanalyse gewonnenen Daten beimessen können, schon deswegen, weil sie vieldeutig sind. Die gepaarten Schwefelsäuren erscheinen im Harn vermehrt bei allerlei Störungen der Darmfunction (Peritonitis, Incarceration, habituelle Obstipation u. s. w.), und wir wissen, dass bei unserem Kranken regelmässig Constipation im Anfalle waltete. Im Aufalle auch nabm er sehr wenig Nahrung und Flüssigkeit zu sich, darum die verringerte Urinmenge.

\section{Ptomainuntersuchung nach der Methode von Griffith. $\left.{ }^{2}\right)$}

a) Der Urin wurde im Anfalle vom 30. Juli und 24 Stunden nach dem Anfalle in sterilisirte Gefässe aufgefangen, auf Eis in dicht verschlossenen Kolben gestellt. Es gelangten zur Verarbeitung $1800 \mathrm{Ccm}$, spec. Gew. 1022. Nach Abdunstung des Aethers erbielt man 0,15-0,20 eines

1) Anleitung zur Harnanalyse. 1893. S. 103.

2) Siehe Hoppe-Segler's Handbuch der physiologisch und pathologisch chemischen Analyse. VI. Aufi. Berlin 1893. 
Weitere Mittheilung über die poroxysmale, familiäre Lähmung.

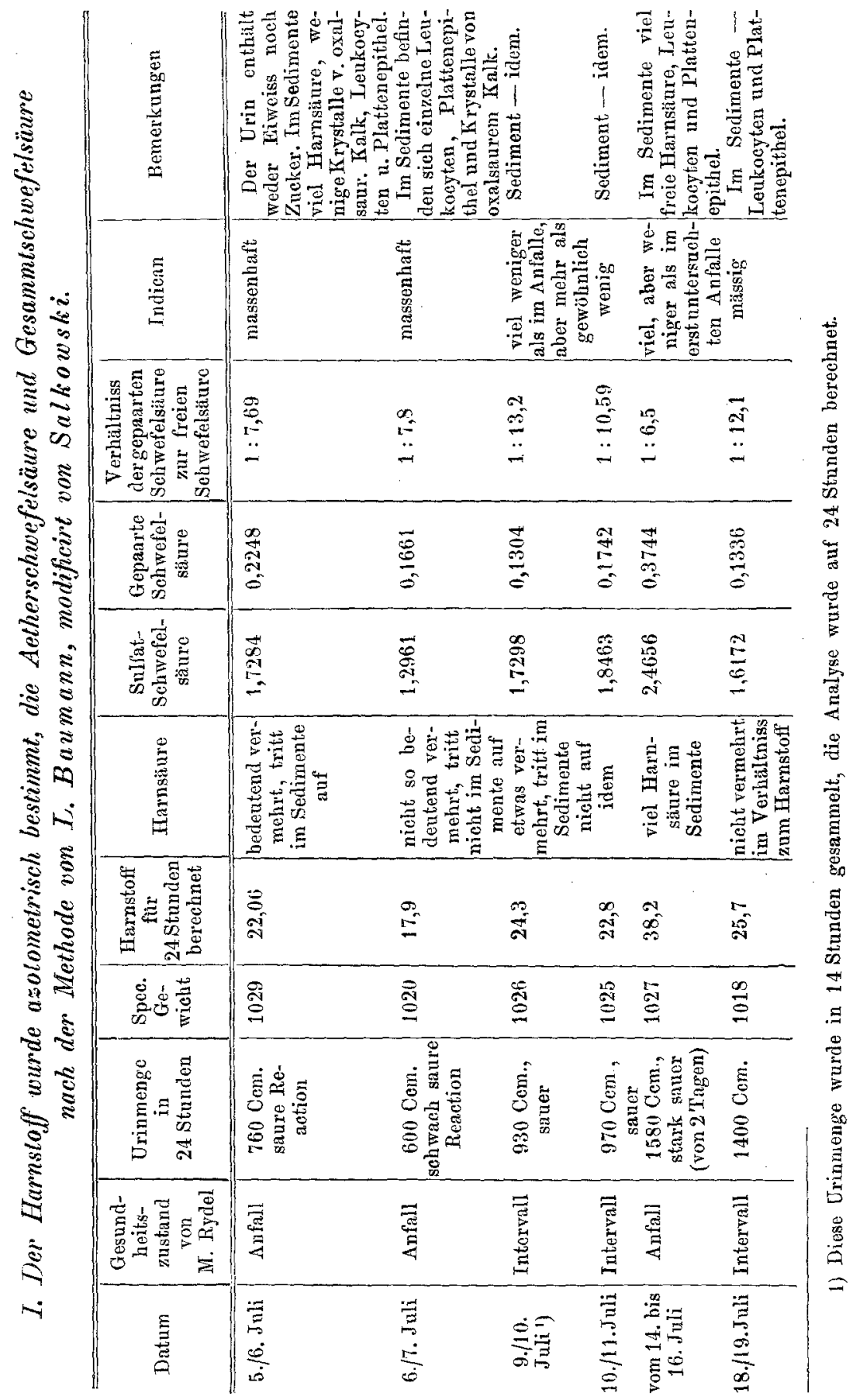


amorphen, weisslichen Pulvers, welches das destillirte Wasser triibte und, dem Kaninchen unter die Haut gespritzt, keine Erscheinungen hervorrief.

b) $3000 \mathrm{Ccm}$. Urin vom Anfalle (25.-26. September) und 24 Stunden nach dem Anfalle, spec. Gew. 1026, wurden, wie oben, zur Verarbeitung auf Ptomaine geliefert. Man erhielt 0,25 eines amorphen Pulvers, welches mit destillirtem Wasser eine milchig trübe Flïssigkeit bildete und, dem Meerschweinchen ins Peritoneum eingespritzt, keine Erscheinungen verursachte.

Da es namentlich erwünscht war, einen biologischen Beweis der Giftigkeit zu erhalten, so unterliess man es, wegen der geringen Menge der gewonnenen Substanz, dieselbe auf Alkaloidreactionen zu prïfen.

\section{Plomainuntersuchung nach Brieger.}

Behufs Untersuchung wurden 20 Liter Harn gesammelt, die tägliche Harnmenge mit $5 \mathrm{Ccm}$. $\mathrm{HCl}$ angesäuert, filtrirt und jedesmal auf dem Wasserbade bis zu Syrupdicke eingedampft. Sämmtliche Portionen wurden in einem Gefässe gesammelt. Ausser morphologischen Elementen blieb manchmal auf dem Filter freie Harnsäure, die in den Anfallsperioden immer stark vermehrt war. Die gesammelte Harnmenge entsprach drei Anfalls- und drei anfallsfreien Perioden. Die syrupdicke Masse wurde nach der Brieger'schen Methode bearbeitet. Der zuletzt erhaltene alkoholische Auszug wurde auf dem Wasserbade getrocknet, der Rückstand mit absolutem Alkohol aufgenommen und die ganze Manipulation 3 mal wiederholt. Der zuletzt in einigen Cubikcentimetern aufgenommene Riickstand stellte sich als eine gelbliche, schwach sauer reagirende Flüssigkeit dar, welche ein feines gelbliches krystallinisches Sediment enthielt. Von dieser Flïssigkeit wurden jedesmal je ein Tropfen zu $5 \mathrm{Ccm}$. destillirten Wassers beigefügt und damit folgende drei Reactionen ausgeführt: 1. nach Zusatz von Pikrinsäurelösung entstand sofort ein krystallinischer Niederschlag; 2. Phosphor-Molybdänsäure rief sofort einen amorphen Niederschlag hervor; nach Zusatz von $\mathrm{NH}_{4}(\mathrm{HO})$ in Ueberschuss zeigte diese Flüssigkeit nach 5 Minuten eine gut ausgesprochene Opalescenz mit schwach blauer Farbe; 3. nach Zusatz schwacher Kali-Bichromatlösung entstand allmählich ein gelblicher Niederschlag. Die weitaus grössere Menge der Flüssigkeit wurde auf dem Wasserbade bis zur Trockne eingedampft; der Rüickstand löste sich in $3 \mathrm{Ccm}$. destillirten Wassers nicht vollständig. Die ganze Lösung wurde bis auf $10 \mathrm{Ccm}$. mit physiologischer NaCl-Lösung verdünnt, mit $\mathrm{HCl}$ schwach angesäuert, wonach der grösste Theil des Sediments sich löste. Die Hälfte dieser Lösung wurde am 27. Januar einem Kaninchen von ca. $2000 \mathrm{Grm}$. in die terminale Ohrvene, die andere Hälfte nach 20 Minuten in die Bauchhöhle eingespritzt. Die Kniereflexe, die elektrische Erregbarkeit, die Beweglichkeit waren bis zum Tode des Kaninchens erhalten. Das Thier frass wenig, magerte stark ab, sein Gewicht betrug am 5. Februar 1450 Grm., nach dem Tode am 13. Febraar nur $1250 \mathrm{Grm}$. Die Section ergab Hyperämie der Leber, Milz, Nieren, Darmes, Adhäsionen des letzteren mit dem Peritoneum. Zur mikroskopischen Untersuchung gelangten der Deltoideus und Biceps und homologe Fragmente eines gesunden Kaninchens; sie wurden in derselben Weise, wie die bald zu be- 
sprechenden Muskeln von Gebr. Rydel, behandelt. Ich fand eine bedeutende Verscbmälerung der Muskelfasern, Kernvermebrung, körnige Oberfläche der Querschnitte, Verstrichensein der Streifung, Veränderungen, die wohl von der starken Abzehrung abhängig sind.

Diesen Versuch kann man als positiv nur in gewissem, bescheidenem Maasse betrachten, da Lähmungen u. s. w. nicht zum Vorschein kamen; der bedeutende Gewichtsverlust (750 Grm.), der sich beim Kaninchen infolge der Einspritzung einstellte, erinnert an diese Kachexie der Thiere nach Einverleiben geringer Mengen von Diphtherietoxine.

Die angegebenen Alkaloidreactionen würden auch darthun, dass wir es im Harne von M. Rydel mit einer ptomainartigen Substanz zu thun hatten. Anf diesem Gebiete, auf welchem unsere Kenntnisse so schwankend sind, ziemt es sich, die grösste Reserve sich anfzulegen. Der Beweis, dass es sich um Toxine handelte, wäre erbracht, hätte das biologische Experiment ein vollkommen positives Resultat geliefert. Indessen haben Ewald und $\mathrm{Jacobs}_{0} \mathrm{n}^{1}$ ) and $\mathrm{Al} \mathrm{bu}^{2}$ ) auf Grund des Befundes eines ptomainartigen Körpers die toxische Provenienz der Tetanie proclamirt; auch diesen Forschern ist es nicht gelungen, den biologischen Beweis zu liefern. Sie suchen dafür manche Erklärung zu geben. In unserem speciellen Falle kommt vielleicht ein Umstand in Betracht, von dem die Rede sein wird, der es verursachte, dass das Thierexperiment den Anfall wie bei unserem Kranken nicht reproducirte.

Die nachstehenden Blutuntersuchungen wurden bereitwilligst von Herrn Coll. Klein, dem ich meinen herzlichsten Dank ausspreche, ausgeführt (s. umstehende Tabelle).

Bei der Durchsicht der Tabelle kann man nicht umbin zu bekennen, dass in den Anfallstagen nüchtern eine mehr oder weniger ausgesprochene Leukocytose bestand; diese Erscheinung schien namentlich in der ersten Zeit der Beobachtung constant bervorzutreten, des Weiteren war sie weniger ausgesprochen, die Leukocytenzahl aber immer eine bohe. Sie schwankte zwischen 14700 und 7320 in den Anfällen, während sie in den Intervallen 6800-9040 betrug, also normal war. Einige Male konnten wir eine Verdauungsleakocytose constatiren, ein anderes Mal stieg die Leukocytenzahl nuichtern auf 19160 in Abhängigkeit von einer frisch sich entwickelnden leichten Typhlitis und Perityphlitis (Appendicitis?).

In Betreff des quantitativen Verhältnisses der diversen Leukocytenformen zeigte das Blut von Rydel sowohl in den Intervallen, als während der Anfälle gewisse Merkmale, die als pathologisch bezeichnet werden muissen. An Stelle von normal vorhandenen 26 bis 30 Proc. kleiner Lymphocyten fand man deren oft in den Intervallen über 40 Proc., also eine exquisite Lymphocytose, gleichzeitig war die

1) Berliner klin. Wochenschr, 1894. Nr. 2.

2) Ebenda. 1894. Nr. 48. 


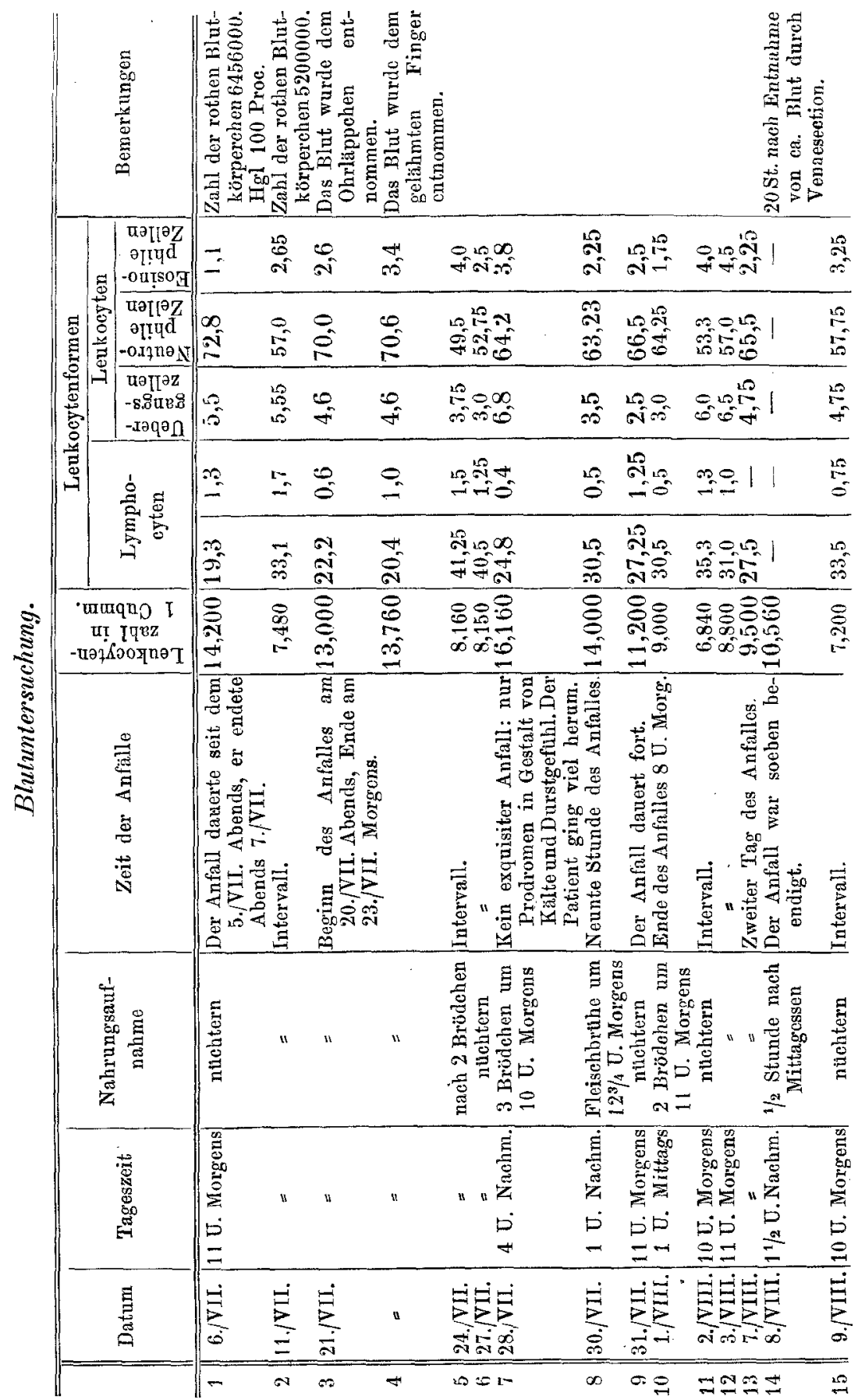


Weitere Mittheilung über die paroxysmale, familiäre Lähmung.
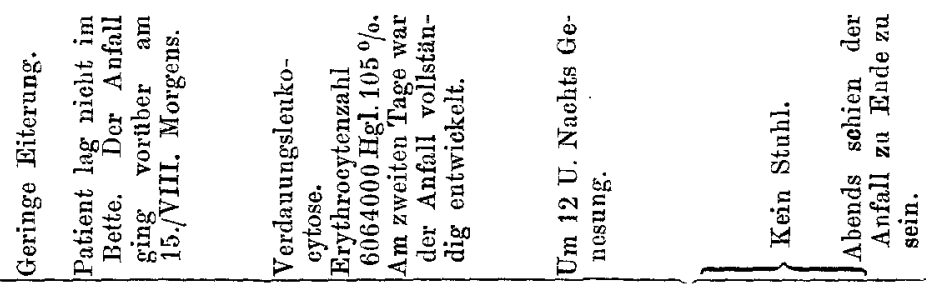

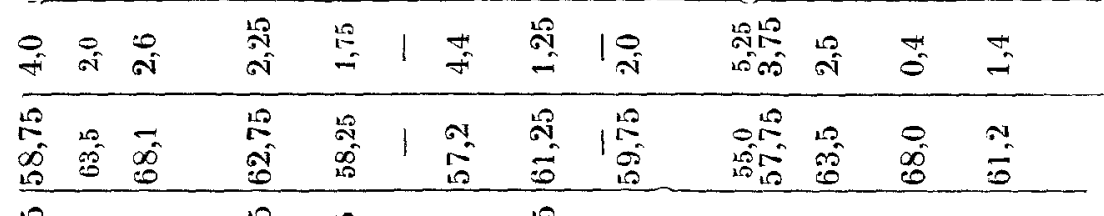

兵 舟

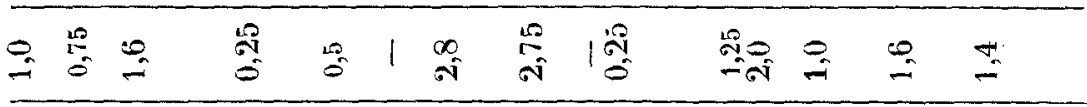

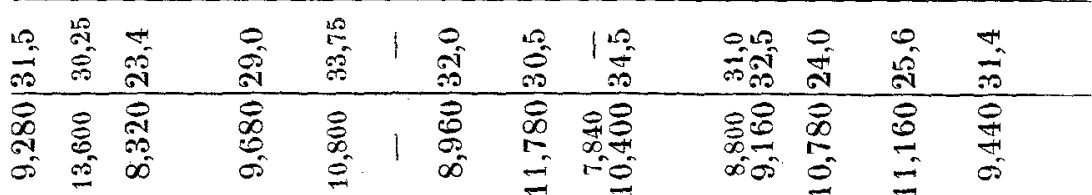

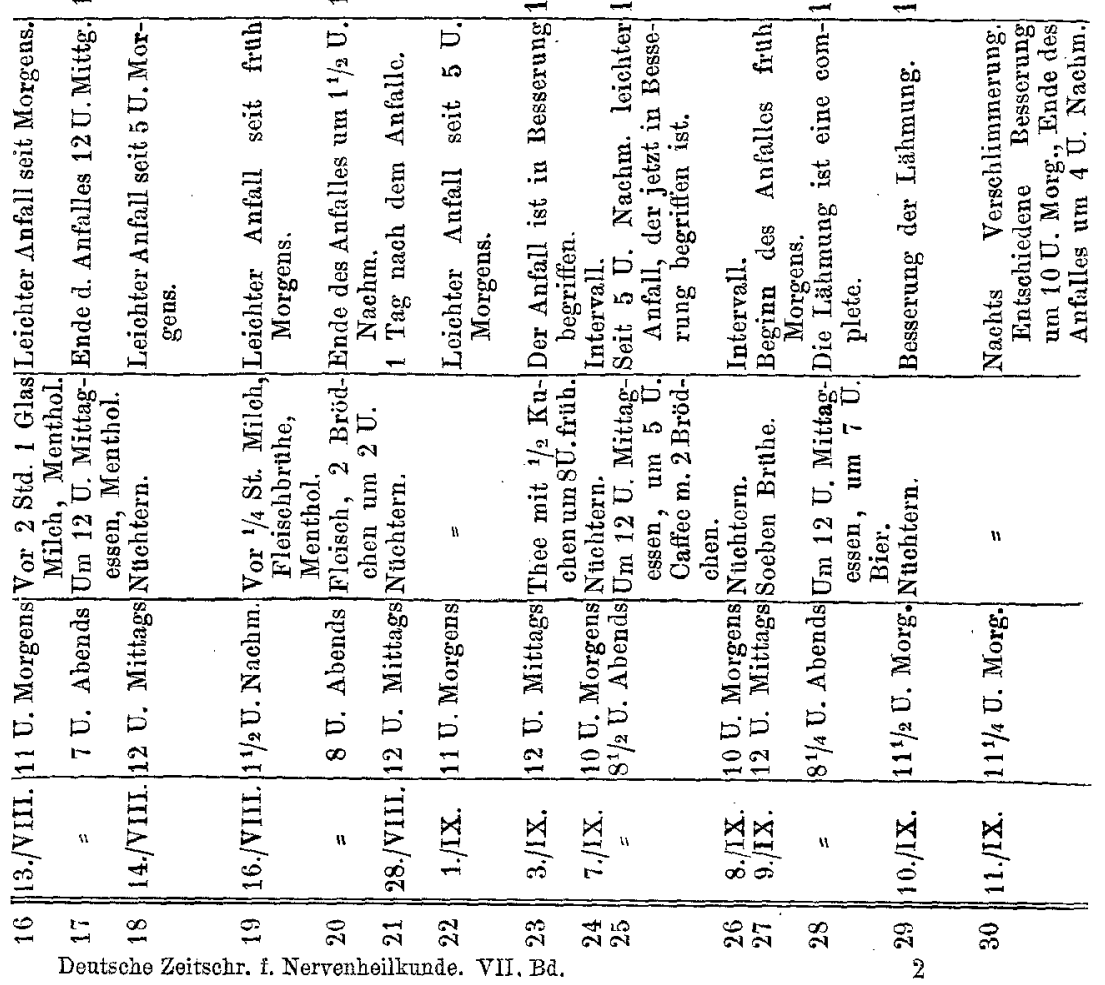




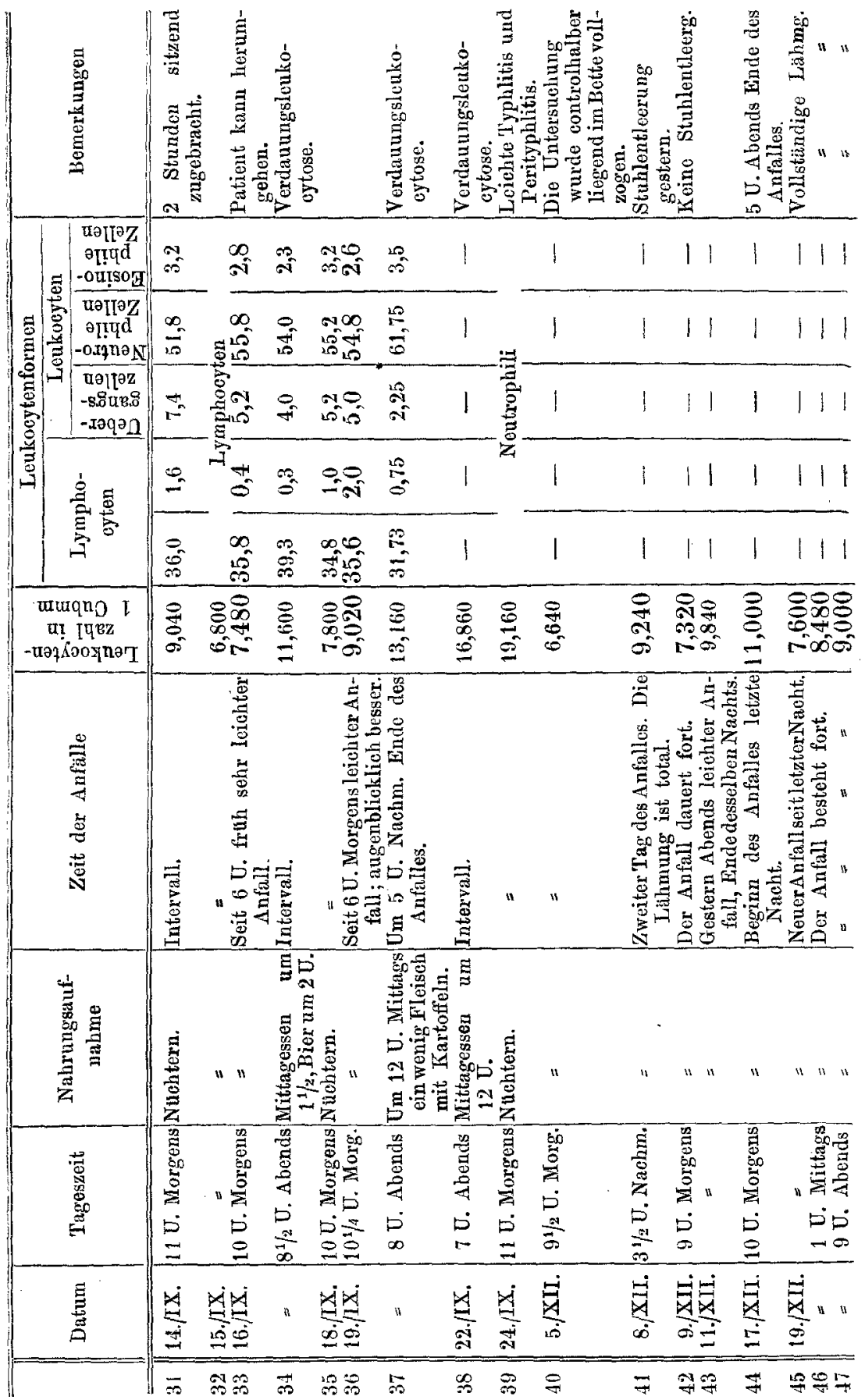


Zahl der eosinophilen Zellen ziemlich bedeutend (manchmal über 5 Proc.). Im Anfalle aber trat eine deutliche neutrophile Leukocytose auf mit Verminderung der Zahl der eosinophilen Zellen.

Um die Frage zu entscheiden, ob die paroxysmale Leukocytose thatsächlich von der den Anfall hervorrufenden Ursache abhängig war, oder aber von anderen, durch die Lähmung selbst bedingten Umständen, z. B. von der Blutstauung in den geläbmten Gliedern, von der die Lähmung begleitenden Koprostase, von der Rückenlage wurden Controluntersuchungen angestellt, die gezeigt haben, dass die genannten Factoren auf das Zustandekommen der Leukocytose keinen Einfluss ausiibten. So z. B. ergab die Untersuchung (Anfall vom 21. Juli) des von dem gelähmten Arme und dem Ohre gleichzeitig entnommenen Blutes beinahe ibereinstimmende Resultate ( 13000 und 13700 ), so betrug die Leukocytenzahl am 5. December (freier Intervall) nach nächtlicher Ruhe noch im Bette nur 6640. Koprostase war ebensowenig von Einfluss, da die Leukocytose auch dann hervortrat, wenn der Kranke Stuhlentleerung vor und während des Anfalles hatte.

Wir sind, so scheint es, berechtigt anzunehmen, dass die mit dem Anfalle hervortretende, in dem Anfalle fortdauernde, mit Ende des Anfalles verschwindende Leukocytose eine ziemlich constante Erscheinung des Krankheitsbildes darstellt, welche durch dieselbe Ursache bedingt wird, die auch die Lähmungsanfälle hervorruft; das deutlich veränderte quantitative Verhältniss der diversen Leukocytenformen in der Zwischenzeit spräche auch dafür. $\mathrm{Da}$ in dem untersuchten Falle von einem irgendwie bekannten, die Leukocytose hervorrufenden infectiösen Krankheitserreger nicht die Rede sein kann, so bleibt die Vermuthung nahe, dass die Leukocytose bei Rydel durch eine Intoxication mit einer, sei es von dem Magendarmkanal ins Blut aufgenommenen, sei es an irgend einer anderen Stelle des Körpers producirten Substanz bedingt wird.

Eine wichtige Ausbeute für die Pathologie des Leidens hat die weitere Untersuchung gebracht. Bei solcher eigenartiger Läḥmung, wie in unserem Falle, mit Aufhebung der elektrischen Erregbarkeit, der Reflexe und Erhaltensein der Sensibilität musste ja die Aufmerksamkeit in erster Linie auf die Beschaffenheit der Muskeln gelenkt sein. Im Jahre 1890 sträubte sich der Kranke energisch gegen irgend welchen, auch winzigsten blutigen Eingriff, da ihm der Todesfall seines, nach der Venaesection gestorbenen, 17 jährigen Cousins noch lebhaft vor den Augen schwebte. Diesmal gelang es mir nicht allein von M. Rydel, sondern auch von Sz. Muskelstückchen zu erhalten, und zwar 
entnahm ich dem M. R. ein erbsengrosses Stück von der Mitte des Deltoideus dexter, dem Sz. R. ron der Grenze des unteren Drittels des rechten Triceps brachii. Die bellrothen Muskelstuckchen wurden sofort nach Excision in M üller'sche Flüssigkeit gelegt, 16 Tage lang darin gehärtet und genau nach derselben Methode zur Paraffineinbettung behandelt. Die Mikrotomschnitte wurden mit Hämatoxylin und Eosin, mit Pikrocarmin, Alauncarmin, mit E hrlich'schem Triacid. gefärbt. Als Controlpräparate liess ich von männlichen Leichen rom

Fig. 1.

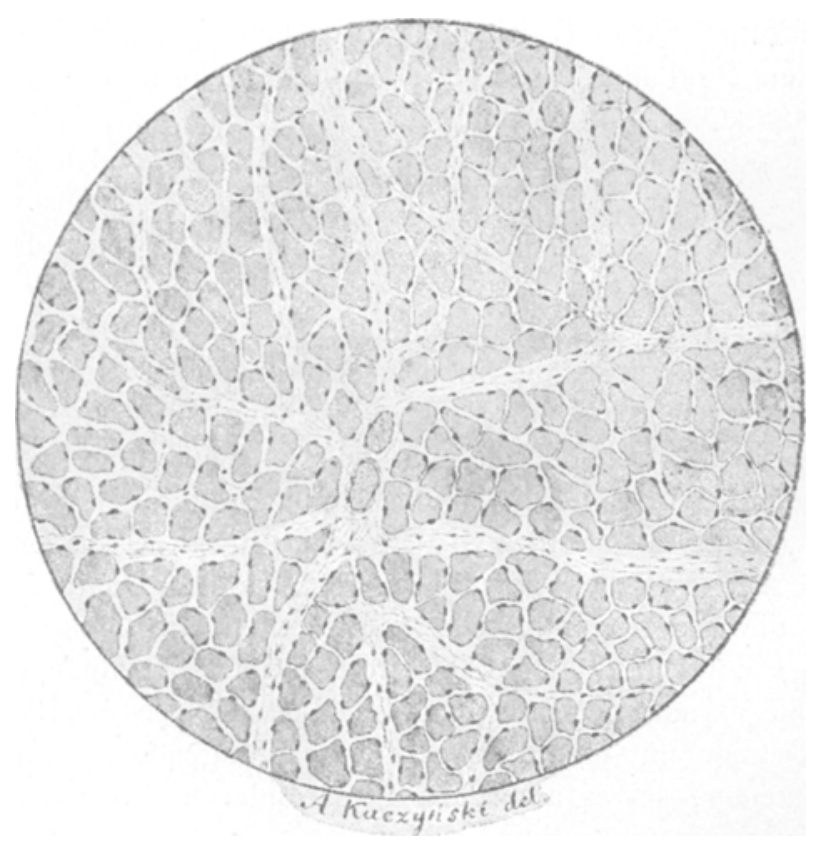

Triceps brachii einer 28 jährigen männlichen Leiche. Zeiss, Apochr. $16 \mathrm{Mim}$. Compens. Oc. 4. Camera luc. Abbé.

selben Alter, mit gut entwickelten Muskeln, gleichnamige Fragmente ganz in derselben Weise behandeln, ausserdem ein, während einer Operation in vivo excidirtes Stïckchen aus dem Biceps brachii eines 26jährigen Arbeiters.

Die beigefügten Zeichnungen stammen vom Triceps brachii des älteren Bruders (Sch. Rydel); zum Vergleich liess ich denselben Muskel einer Leiche abbilden.

Ich kann die Resultate der milkroskopischen Untersuchung gemeinsam für beide Brider besprechen, da die ermittelten Verände- 
Weitere Mittheilung über die paroxysmale, familiäre Lähmung.

rungen ganz identisch sind. Zunächst fällt die ausserordentlich grosse Breite der einzelnen Muskelfasern auf Querschnitten auf, zumal man sie mit Controlpräparaten vergleicht (Fig. 1 und 2). Die Messungen haben folgende Zahlen ergeben.

Deltoideus dexter von M. Rydel Breite der diunnsten Faser $75, \mu$

$=\quad=$ mittelgross. $=109 \mu$

$=\quad=$ dicken $\quad=132 \mu$

Riesenfaser
Deltoideus dexter von Controlpräparaten

$20 \mu$

$33 \mu$

$44 \mu$

Fig. 2.

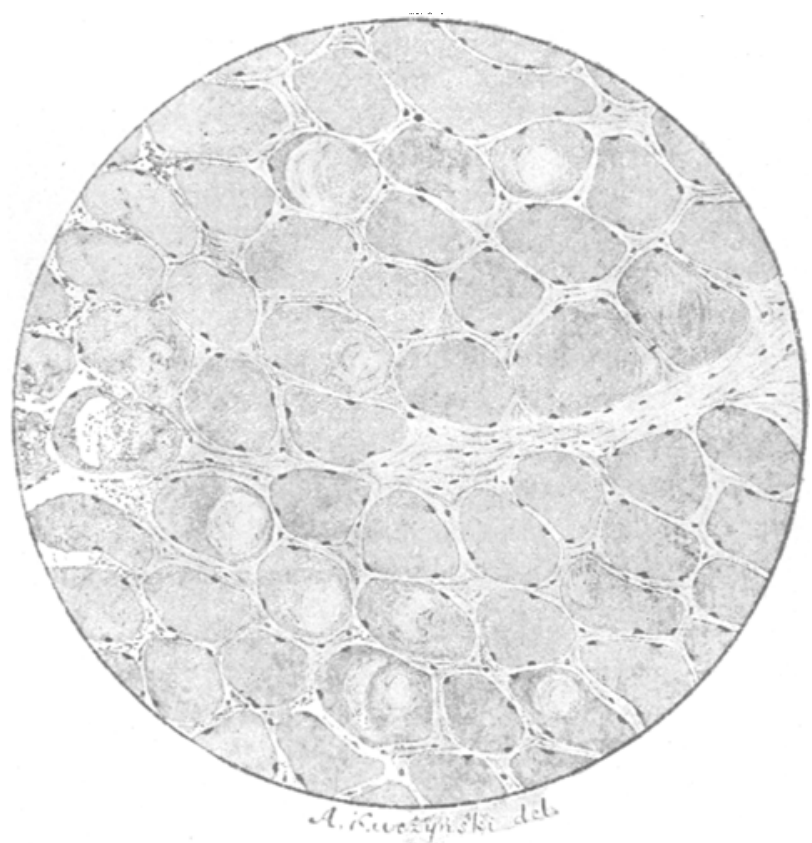

Triceps brachii von Scholka Rydel.

Zeiss, Apochr. $16 \mathrm{Mm}$. Compens. Oc. 4. Camera luc. Abbé.

Triceps dexter von Sch. Rydel

Breite der dünnsten Faser $70 \mu$

$=\quad=$ mittelgross. $=83 \mu$

$=\quad=$ dicken $\quad=122 \mu$
Triceps dexter von Controlpräparaten

$18 \mu$

$28 \mu$

$41 \mu$

Biceps brachii eines 26 jährigen Arbeiters (Dilaceratio brachii)

Breite der dünnsten Faser $26 \mu$

$=\quad=$ mittelgross. $=67 \mu$

$=$ dicken $=104-119 \mu$. 
Frey giebt die Dicke der menschlichen Muskelfaser auf 11 bis $56 \mu$ an, bei Schiefferdecker finden sich die Zahlen $30 \mu$ und $65 \mu_{2}$ bei Kölliker 11-34 $\mu$. Auch bei dem unserigen 26 jährigen Arbeiter bestand die Mehrzahl der Muskelfasern aus den dünnkalibrigen von $26 \mu$ und mitteldicken von $67 \mu$; die dicken Fasern von 104-119 $\mu$ bildeten die Minorität. Wir sehen also, dass der Unterschied im Kaliber ganz bedeutend ist: die dünnste Maskelfaser von den Brüdern Rydel ist beinahe zweimal so dick, als die gröbste in den Controlpräparaten, und ubertrifft um Vieles die von den Autoren angegebenen Zahlen fär Normalfasern. Die Einwände von Oppenheim und Siemerling werde ich weiter unten berïcksichtigen. Es ist auch beachtungswerth in den Präparaten von den Bridern Rydel, dass der Haupttheil aus dicken Fasern besteht, nur wenige zeigen Mittelwerthe. Dieser Gleichmässigkeit der Dicke entspricht auch die Gleichmässigkeit der Gestalt der Querschnitte, die meistens abgerundet und oval erscheint; man sieht keine vielgestaltige, polygonale Formen, wie normal.

Die Oberfläche der querdurchscbnittenen Fasern hat kein undulirtes Aussehen wie normal, sie erscheint glatt und lässt meistens den feineren Ban ans Primitivfibrillen schon bei mittleren Vergrösserungen erkennen (Fig. 3). Solche Fasern sehen im ganzen Querschnitte oder in einem Theile desselben blasser aus; die Primitivfibrillen stellen sich als Pünktchen, oder Strichelchen, wenn der Schnitt etwas schräge ausgefallen ist, dar, die durch durchsichtiges Gewebe, oder Flüssigkeit getrennt sind. Die Primitivfibrillen sind gleichsam durchtränkt, auseinandergeschoben, rareficirt. Diese, sagen wir, Rarefaction der Muskelfaser nimmt entweder den ganzen Querschnitt ein, oder nur ein Segment, oder den centralen Theil des Querschnittes, einen Saum homogeneres Gewebe übrig lassend; in den letzteren Fällen ist die Grenze gewöhnlich halbmondförmig und scharf markirt. Solche Bilder mit rareficirtem Gewebe trifft man namentlich zahlreich an Präparaten, die vom älteren Bruder stammen.

Als wahrscheinlich höhere Stufe desselben pathologischen Processes der Rarefaction muss die zahlreich vorhandene Vacuolenbildung angesehen werden. Sie stellt meistens runde oder ovale, kleinere und grössere, scharf contourirte, manchmal wie mit zarter Membran ausgekleidete Lücken im Querschnitte dar, welche durch eine structurlose, körnige oder glasige, wie geronnenes Eiweiss aussehende Masse mehr oder weniger vollständig gefüllt sind, oder aber leer erscheinen. Manchmal sieht man an einer Muskelfaser die zwei Processe der Rarefaction und Höhlenbildung, gleichsam die Entstehung der letzteren aus der ersten. Gewöhnlich befindet sich nur eine Vacuole in dem Querschnitte der Muskelfaser, nicht selten aber deren mehrere, sogar drei in einem Querschnitte. Ebenso wie die Rarefaction, ist die Vacuolenbildnng bei dem älteren Bruder eine ausgesprochenere.

Auf Längsschnitten ist die Quer- und Längsstreifung meistens deutlich. Das rareficirte Gewebe stellt sich in Form von helleren Ringen dar, die die 
Weitere Mittheilung über die paroxysmale, familiäre Lähmung.

Fig. 3.

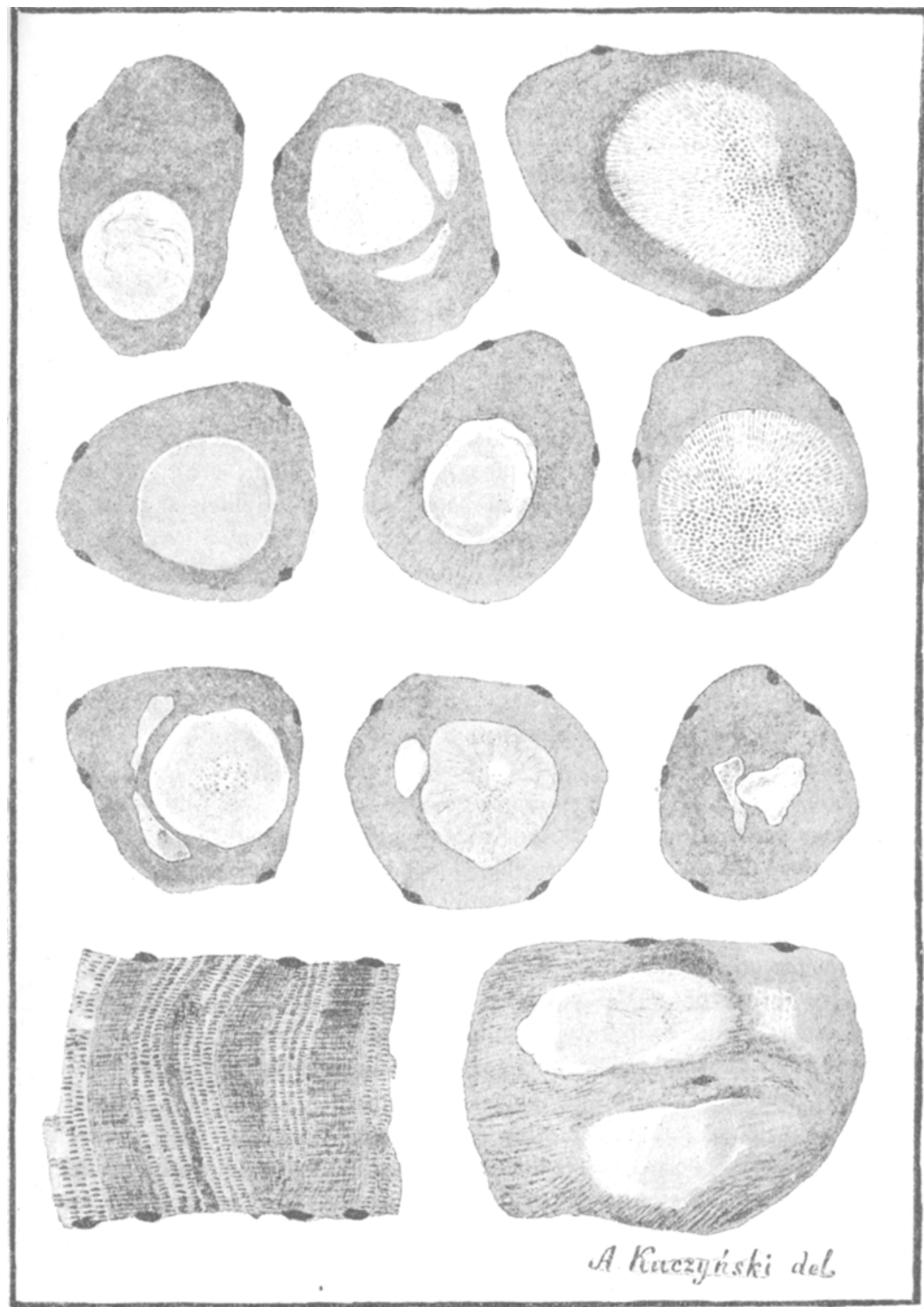

Triceps brachii von Sch. Rydel. Stärk.Vergröss. Zeiss, Apochr. $4 \mathrm{Mm}$. Comp. 0c. 4. Cam. luc. Abbé. Tubuslänge $150 \mathrm{Mm}$. 
ganze Breite der Faser oder nur einen Theil derselben einnehmen und die die Streifung noch deutlicher erkennen lassen. Es kommen dadurch Bilder zu Stande, die auf den ersten Blick als Artefact, als Falten imponiren können. Bei näherer Betrachtung aber kommt man zur Ueberzeugung, dass diese Ringe einen pathologischen Vorgang darstellen, da sie in einem Niveau mit den angrenzenden Partien der Muskelfasern liegen und nicht immer die ganze Breite der Faser einnehmen. Auf Controlpräparaten von in vivo excidirten Muskelstückchen und von der Myotonia congenita habe ich solche Bilder nicht gesehen. Die Vacuolen haben auf Längsschnitten gewöhnlich eine länglich-ovale Form.

Das intramusculäre Bindegewebe scheint nicht vermehrt; vielleicht sind die bindegewebigen Streifen etwas breiter als normal. An den Gefässen war nichts Abnormes zu finden. Ich habe leider kein grösseres Nervenbündel angetroffen. Die Zahl der Sarcolemmakerne schien nicht vermehrt, vielleicht waren sie auf Querschnitten dicker als normal.

Wie auch die oben angeführten Zahlen zu Gunsten einer Hypertrophie der Muskelfasern sprechen mögen, so scheint doch ibre Bedeutung in gewissem Maasse eine Einschränkung erleiden zu müssen im Lichte der Untersuchung von 0 ppenheim und Siemerling ${ }^{1}$, welche gezeigt hat, dass die Durchschnittsmaasse der Muskelfasern der in vivo excidirten Fragmente grösser sind, als die der Leiche entnommenen, dass in den Präparaten von bei Lebzeiten erhaltenen Muskelfragmenten neben gewöhnlichen Durchschnittsmaassen sich fast immer eine Anzahl entschieden hypervoluminöser Fasern findet in Fällen, wo von einer Muskelaffection die Rede nicht sein kann. Auch ich habe am Biceps brachii des 26 jährigen Arbeiters (Dilaceratio brachii) auffallend hypervoluminöse Fasern gefunden, sie bildeten aber weitaus nicht die Mehrzahl, im Gegentheil die mittelstarken, namentlich aber die dünnen waren am meisten vertreten. Nach diesen Untersuchungen muss der Einfluss der Excision am lebenden Menschen auf Grösse, Gestalt u. s. w. einer Anzahl von Primitivfasern zugestanden werden; neben hypervoluminösen Fasern giebt es aber viele Fasern mit gewöhnlichen Durchschnittsmaassen. Ein auffallendes Merkmal aber in den Präparaten von den Gebruider Rydel bestand darin, dass keine einzige Faser mit gewöhnlichem Durchschnittsmaass zu finden war, dass alle gleichmässig zu den dickkalibrigen zählten, neben welchen Riesenfasern sich befanden. Ich muss also diesen gleichmässig hypertrophischen Muskelfasern bei den Brüdern Rydel den Werth als eines pathologischen Befundes beimessen. Dass es sich überhaupt um ausgesprochen krankhafte Veränderungen in den Muskeln handelt, kann ja sonst keinem Zweifel unterliegen, in Anbetracht der

1) Centralblatt für die medic. Wissenschaften. 1889. S. 705 u. 737. 
Rarefaction und Vacuolenbildung, die ja entschieden pathologische Vorgänge sind.

Die mikroskopische Untersuchung der excidirten Muskelstückchen hat also ubereinstimmend bei beiden Brüdern, nur intensiver beim älteren, Hypertrophie der Muskelfasern, Rarefaction der Primitivfibrillen und Vacuolenbildung ergeben. Durch diesen Befund werden die enormen Veränderungen der elektrischen Erregbarkeit auch in den lähmungsfreien Intervallen dem Verständnisse näher gerïckt. Man wird wieder zum Vergleich mit der Thomsen'schen Krankheit, in welcher von Erb ebenfalls Vacuolenbildung und Hypertrophie der Muskelfasern ermittelt wurden, gedrängt. E r b giebt Zahlen über $180 \mu$ an, daneben waren, wenn auch nicht zahlreich, dünne Fasern unter $40 \mu$ vorhanden, die bei uns fehlten. Es bestehen aber bedeutende Untersehiede in dem mikroskopischen Bilde. Die Primitivfibrillen sind in der Myotonia congenita bei mittleren Vergrösserungen nicht sichtbar, hier scheinen sie durch eine durchsichtige Flüssigkeit auseinandergeschoben, wie rareficirt. In der Thomsen'schen Krankheit ist auf Längsschnitten die Streifung fein, oft undeutlich, hier ist sie namentlich an den rareficirten Stellen ungemein deutlich. Dort starke Kernvermehrung, leichte Hyperplasie des Bindegewebes mit körniger Einlagerung, hier sind diese Erscheinungen nicht vorhanden.

Von der Dystrophia muscularis progressiva, bei welcher ebenfalls viele breite Muskelfasern vorkommen, unterscheidet sich der geschilderte Befund dureh das Vorhandensein bei der ersten Krankheit vieler schmalen, auffallend dünnen Fasern, der Kernvermehrung, der Hyperplasie mit Kernwucherung des interstitiellen Bindegewebes, der Fetteinlagerung, durch das Fehlen von Vacuolen u. s. w.

Wie auffallend auch die eruirten Anomalien der Muskelstructur, der elektrischen Erregbarkeit sein mögen, so will ich doch daran erinnern, dass sie in der vergleichenden Physiologie and Anatomie nicht ohne jedes Analogon sich befinden. Diese Daten, die theils schon von Erb in seiner Monographie über die Thomsen'sche Krankheit zusammengestellt sind, haben namentlich Bezug auf abnorme elektrische Reactionen bei manchen Thierarten. Es ist eine längst bekannte Thatsache, dass bei gewissen niederen Thieren die Contractionsform der Muskeln eine viel trägere und deutlich nachdauernde ist. Nach den Angaben von Ch. Richet contrahiren sich die Schwanzmuskeln des Flusskrebses rasch, kuz, blitzähnlich, sie gerathen in Te nur bei rasch aufeinanderfolgenden Reizen und ermiden rasch, die Scheerenmuskeln dagegen contrahiren sich viel langsamer, träge, zeigen lange Nachdauer der Contraction, verfallen in Te schon bei seltenen Reizen, 
zeigen keine Ermüdung. Ranvier fand, dass die rothen Muskeln bei Kaninchen und gewissen Fischen nach längerer Latenzzeit sich träge contrahiren und langsam erschlaffen bei faradischer Reizung, während die weissen sich ebenso rasch contrahiren, wie sie erschlaffen. Auch bistologisch fanden sich in den Muskeln erhebliche Differenzen. Soltman macht die sehr interessante Angabe, dass die Muskeln neugeborener Thiere (Kaninchen, Katzen, Hunde) sich viel träger zusammenziehen, die Ausdehnung viel langsamer geschieht, als bei älteren Thieren. Neulich bat Westphal ${ }^{1}$ ) auch beim Menschen Untersuchungen in dieser Hinsicht angestellt, die ergaben, dass in den ersten Wochen bei Neugeborenen eine starke Herabsetzung der indirecten faradischen und galvanischen, der directen faradischen Erregbarkeit obwaltet; galvanische Ströme von einer Stärke, die beim Erwachsenen längst Tetanus hervorbringen, rufen nur schwache Zackungen hervor. Nach der 5. Woche ist Herabsetzung der Erregbarkeit nicht mehr deutlich nachzuweisen. Die Zuckung ist für den galvanischen und faradischen Strom deutlich träge. Der Hautwiderstand ist in der ersten Woche sehr erheblich. Nur wenige Nerven Neugeborener besitzen Markscheiden; wo sie vorhanden, zeigen sie grosse Unterbrechungeu. Die Kerne der Schwann'schen Scheide sind sehr gross, die Faser dünner als beim Erwachsenen. Die Muskelfasern Neugeborener sind fast kreisrund, werden erst allmählich polygonal.

Ich mache namentlich auf die zuletzt angeführten Untersuchungen von Westphal aufmerksam; eine gewisse Aehnlichkeit zwischen diesen Befunden bei Neugeborenen und den oben bei unseren Kranken geschilderten ist unverkennbar. Hier und dort Alteration der elektrischen Erregbarkeit, träge Zuckung, rundliche Muskelfasern. Man könnte auf den Gedanken kommen, dass in manchen Familien die Ausbildung der Muskeln beim Erwachsenen auf einer frühen Entwicklungsstufe, auf der des Neugeborenen, stehengeblieben ist. -

Fassen wir in wenigen Worten das Facit der Untersuchungen zusammen, so haben wir es mit einer exquisit familiären, auf gleichartige Vererbung beruhenden Krankheit zu thun, die im jugendlichen Alter auftritt, sich in anfallsweiser, schlaffer, totaler Lähmung der Glieder, des Rumpfes, mit Herabsetzung resp. Aufhebung der Reflexe, der mechanischen und elektrischen neuromusculären Erregbarkeit kundgiebt. In der Zwischenzeit fühlen sich die Betroffenen vollkommen gesund, objectiv aber ist die geringe grobe Kraft der volaminös entwickelten Musculatur auffallend, der Nervenmuskelapparat zeigt ganz bedeutende

1) Neurolog. Centralblatt. 1894. Nr. 2. 
Abweichungen der elektrischen Erregbarkeit, die man als eine Abart der partiellen Entartungsreaction mit indirecter Zuckungsträgheit bezeichnen kann, die Sehnenreflexe, die idiomusculäre mechanische Reizbarkeit sind qualitativ verändert. Die mikroskopische Untersuchung endlich der frisch excidirten Muskelstïckchen ergiebt ebenfalls ganz erhebliche Veränderungen der Structur, als Hypervolumen der Muskelfasern, Rarefaction der Primitivfibrillen und Vacuolenbildung. Es kann wohl keinem Zweifel unterliegen, dass die abnormen mechanischen und elektrischen Reactionen, die Lähmungsanfälle selbst im innigen, causalen Zusammenhange mit der genannten Structuralteration der Muskeln zu stellen sind.

Durch diesen Muskelbefund ist die paroxysmale Lähmung aus der Reihe der Neurosen geschieden; sie tritt in das immer sich erweiternde Gebiet der auf organischen Störnngen beruhenden Erkrankungen, speciell muss sie in die grosse Kategorie der bereits bekannten familiären (mit gleichartiger Vererbung) Erkrankungen eingereiht werden, als welche die Dystrophia muscularis progressiva, die neurotische Muskelatrophie H offmann's, die Frie drei ch'sche Krankheit, die Myotonia congenita zu nennen sind.1) Mit der letzteren namentlich hat die paroxysmale Lähmung die meisten Analogien. Beide Krankheiten wurzeln tief in der Ascendenz, bei den Betroffenen fällt hier und dort die stark entwickelte Musculatur auf bei verbältnissmässig geringer Kraft, die Functionsstörung tritt in beiden Krankbeiten nur zeitweise anf, Ruhe ist für beide ein begünstigendes Moment, Bewegung löst den Krampf in der Thomsen'schen Krankheit, die motorische Schwäche in der paroxysmalen Lähmung, in beiden sind permanent Veränderungen der elektrischen und mechavischen Erreg-

1) Ich finde im Centralblatt für innere Medicin 1894. Nr. 46 ein Referat über die Arbeit von Rich, "A unique form of motor paralysis due to cold“ (Med. News. 1594. August 28), in welcher über eine merkwürdige krankhafte Disposition berichtet wird, die darin besteht, dass unter dem Einflusse der Kälte, besonders nasskalter Witterung, die am nächsten und zunächst diesen Agentien ausgesetzten Muskelgruppen in einen Zustand tonischen Spasmus gerathen mit Fixation bald in Benge-, bald in Streckstellung. Am häufigsten ergriffen sind die Muskeln des Gesichts, aber auch die Extremitäten, die Zunge, Schlundmuskeln. Die Affection betrifft nur ruhende Muskeln, dauert verschieden lang, eine halbe, zwei und mehr Stunden; in der Regel schwindet die Rigidität erst nach Anwendung der Wärme. Die Affection ist nur bekannt unter den Gliedern der Familie des Verfassers, welcher den Stammbaum ron 4 Generationen anführt, und unter 56 Gliedern bei 22 die geschilderte Disposition gefunden hat. Er nimmt eine ererbte krankhafte Disposition der motorischen Endplatten an. Dieses interessante Krankheitsbild scheint mir in die hier in Betracht gezogene Kategorie zu gehören und namentlich mit der Myotonia congenita verwandt zu sein. 
barkeit vorhanden, auch ist die Muskelläsion sehr ähnlich. Nicht minder gross sind die Differenzen beider Krankheiten; bei der Myotonie Krampf im Beginne der Bewegung, hier paroxysmale, vollständige Lähmung mit Herabsetzung resp. Aufhebung der Reflexe, der mechanischen und elektrischen neuromusculären Erregbarkeit, die die Cerebralnerven, entgegengesetzt der Thomsen'schen Krankheit, unbetheiligt lässt. Ueber die feineren Unterschiede in dem Verhalten der Nerven und Muskeln ausserhalb der Anfälle gegenüber den elektrischen Strom and in dem Muskelbefunde wurde bereits oben berichtet.

Die mitgetheilten Untersuchungen, namentlich aber die eminente Wichtigkeit der Muskelläsion, scheinen die Annahme zu berechtigen, dass die paroxysmale Lähmung ein primär myopathisches Leiden darstellt; es liegt einstweilen kein Grund vor, ein centrales Leiden anzunehmen. Erb hat bekauntlich für die Thomsen'sche Krankbeit manche Gründe angeführt, nämlich den engen Zusammenhang und die vollständige Abhängigkeit der Muskeln vom Nervensystem in functioneller und trophischer Beziehung, die Heredität a. s. w., die dafür sprechen, dass das Leiden in letzter Instanz vom Nervensystem ausgeht; mit grösserem Nachdruck hat er diese Hypothese für die Dystrophia musculorum progressiva verfochten. In Anbetracht der nahen Verwandtschaft der Thomsen'schen Krankheit mit der paroxysmalen Lähmung müssen wir auch die Hypothese des neuropathischen Ursprungs in Erwägung ziehen. Nun aber hat die postmortale Untersuchung eines Falles von Myotonia congenita durch Dejerine et Sottas ausschliesslich Muskelveränderungen ergeben, das Nervensystem erwies sich vollkommen intact. Die Untersuchung von Le onowa $\mathrm{w}^{1}$ ) an Föten mit vollständigem Mangel des Rückenmarks haben gezeigt, dass die quergestreifte Musculatur ganz normal entwickelt war, ein Beweis der Selbständigkeit der Muskeltrophik und Unabhängkeit vom Centralnervensystem. Was die Heredität anbelangt, so kann ja die anomale Anlage nicht allein das Nervensystem, sondern auch das Muskelsystem betreffen.

Die Abart der partiellen Eak mit indirecter Zuckungsträgheit spräche auch zu Gunsten des myopathischen Ursprungs, da nach $\mathrm{Erb}^{2}$ ) die Ursache der partiellen EaR mit indirecter Zuckungsträgheit in die Erkrankung der Muskelsubstanz selbst zu verlegen sei. Doch fehlen in dieser Beziehung positive anatomische und experimentelle Beweise, und Erb bekennt, dass Veränderungen im Nerven mit voller Sicherheit nicht auszuschliessen sind.

1) Neurolog. Centralblatt. 1894. Nr. 20.

2) Ebenda. 1883. Nr. 8 . 
Es ist wohl nicht unmöglich, dass künftighin ausser der Muskelläsion noch nervöse Alterationen, z. B. in den Endplatten ermittelt werden. Unsere frühere Anschauung, die das Leiden in diese Gebilde und in die Muskeln verlegte, hat insofern Bestätigung erfahren, dass bedeutende Veränderungen in den letzteren in der That eruirt wurden. Wenn für das ganze Verständniss der Krankheit somit ein materielles Substrat gewonnen wurde, so können wir uns nicht verhehlen, dass über das Zustandekommen der Lähmungsanfälle selbst wir wenig unterrichtet sind. Wir müssen zwar annehmen, dass die eruirte Muskelläsion eine unerlässliche Vorbedingung derselben bildet, dass aber zum Ausbrucli der so charakteristischen Lähmungsanfälle noch andere Factoren hinzukommen. Welche aber diese sind, welche occasionelle Momente mitspielen, ihre Wirkungsweise u. s. w., darüber wissen wir wenig. Wir wissen nur, dass Ruhe, namentlich aber Schlaf ein in höchstem Grade beguinstigendes Moment darstellt, es ist dies in geringerem Grade der Fall für Wärme, Sommersaison und Gemüthsbewegungen. Locomotion wirkt entschieden anfallswidrig.

Wir müssen zugeben, dass die Hypothese einer Giftwirkung sich am besten mit dem ganzen Bilde verträgt: das schnelle Einsetzen der Lähmung unter prodromalen Erscheinungen, die ausschliessliche Betheiligung fast der sämmtlichen Musculatur, das Verschwinden der Reflexe und elektrischen Erregbarkeit, die rapide Herstellung u. s. w. weisen auf eine Giftwirkung hin. Eine gewisse Stiutze hat diese Hypothese in dem Befunde eines ptomainartigen Körpers im Urin von unseren Kranken erhalten. Betonen möchten wir aber, dass das Thierexperiment, dieses feinste und beweisendste Reagens, in gewissen Maasse im Stiche liess, da es das charakteristische Krankheitsbild nicht zu reproduciren vermochte. Zugegeben muss werden, dass wir es in unserem Falle noch mit complicirteren Verhältnissen, nämlich mit krankhaft veränderter Musculatur zu thun haben. Ferner war es die ziemlich constant im Anfalle erscheinende Leukocytose, die zu Gunsten einer Giftwirkung sprach.

Es liegen manche physiotoxicologische Erfahrungen vor, die, falls es sich um eine Giftwirkung handelt, die Erscheinungen bei unseren Kranken dem Verständniss ein wenig näher rücken. Schon Erb führt in seiner Monographie über die Thomsen'sche Krankheit an, dass die quergestreiften Muskeln niederer und böherer Thiere auf verschiedene Einflüsse mit einer A enderung der Zuckungsform reagiren, welche sich als Verlängerung. aller Stadien der Zuckungen, als träge, tonische, nachdauernde Contractionen charakterisirt. In dieser Beziehung seien zu erwähnen die Einwirkung der Kälte, der Einfluss des Ermüdens 
und Absterbens, die Einwirkung gewisser chemischer Substanzen und Gifte als Veratrin, Physostygmin, Digitoxin, Coffeïn, Antiarin, Natriumphosphat. Protoveratrin ${ }^{1}$ ) soll in einem gewissen Stadium seiner Wirkung eine Erschöpfbarkeit der Muskeln hervorrufen. Speciell sei auf die Aehnlichkeit unseres Krankheitsbildes mit Curarelähmung: hingewiesen. Ross b a h beobachtete, dass beim Kaninchen bei kleinen Curaregaben die vom Nerven aus erhaltenen Maximalzuckurgen grösser wurden, als vor der Vergiftung; steigert man die $\mathrm{Ca}$ raredosis, so werden die Zuckungen niedriger, bis zum völligen Verschwinden.

Auch beim Menschen hat man analoge Beobachtungen gemacht. Mosso ${ }^{2}$ ) hat gefunden, dass bei gesunden Menschen, welche das Gehirn durch geistige Arbeit ermüden, gleichzeitig eine Ermüdung der in der Ruhe gebliebenen Muskeln eintreten kann und zwar eine Ermüdung, welche sich als gesteigerte Erschöpfbarkeit nicht nur bei willkiurlicher Arbeitsleistung, sondern auch bei directer Muskelreizung durch den elektrischen Strom bemerkbar macht. Mosso nimmt an, dass es sich hierbei um chemische Aenderungen im Muskel handelt, welche durch die bei der Gehirnarbeit sich entwickelnde Stoffwechselproducte bewirkt wird.

Ebenso wie oben darauf hingewiesen wurde, dass sowohl die Muskelläsion, als Abart der partiellen Eak mit indirecter Zuckungsträgheit ihre pathologischen und physiologischen Analoga finden, so sollen die eben angeführten Thatsachen in dem Sinne gedeutet werden, dass für die präsumirte toxische Lähmung ebenfalls Analogien herangezogen werden können.

Man müste sich die Sache in der Weise denken, dass das Gift, welches vornebmlich in der Ruhe gebildet wird, nur auf in gewisser, charakteristischer für die paroxysmale Lähmung, Weise veränderte Muskeln seine starke functionsherabsetzende Wirkung entfaltet. Wir sahen ja, dass die directe elektrische Erregbarkeit im Anfalle hochgradiger herabgesetzt war, als die indirecte. Vielleicht sind es am Ende gar normale Stoffwechselproducte, die nur auf solche Muskeln wie bei der paroxysmalen Lähmung deletär einwirken; durch solche Voraussetzung würde das Scheitern unserer Bemühung, eine Giftwirkung zu veranschaulichen, erklärlich sein.

Ich muss dem Einwande entgegenkommen, dass, angenommen dass es sich in der That um eine Giftwirkung handelt, die eruirte Muskelläsion dann vielleicht in Abhängigkeit davon zu stellen sei und als Folgezu-

1) Citirt nach Jolly, Berliner klin. Wochenschr. 1895. Nr. 1.

2) Ebenda. 
stand der toxischen Einwirkung betrachtet werden könnte; für solche Interpretation könnte man die Thatsache heranziehen, dass bei M. Rydel vor 4 Jahren die Veränderungen der elektrischen Erregbarkeit nur auf manche Muskelterritorien beschränkt waren, und meinen, dass mit Wiederholung der Anfälle die Muskelalteration eine ausgebreitetere wird. Gegen solche Deutung müsste ich entsehieden mich verwahren, denn wie sollte man die Thatsache erklären, dass beim älteren Bruder, bei welchem in den letzten 3 Jahren die Anfälle jedenfalls viel seltener auftraten, die Muskelläsion und die Anomalien der elektrischen Erregbarkeit dennoch ausgesprochener waren, als beim jüngeren, so oft von Anfällen beimgesuchten Bruder; wie soll man die exquisite gleichartige Heredität u. s. w. erklären?

In therapeutischer Hinsicht kann ich leider nichts Erfreuliches berichten. Weder Desinficientia des Darmkanals, noch irgend welche Diät, oder Medicamente wie Strychnin, Ergotin, Arsen u. s. w., Massage, Elektrisation, Bäder u. s. w. hatten irgend welchen Einfluss. 